aortic clamp times. We ensure that the allograft sits deep inside the annulus, performing a tension-free allograft to distal aorta anastomosis and wedging the larger end rather than trying to make up for size mismatch, and pack the surgical field for 30 minutes (without use of suction) after starting protamine.

Well-described techniques to minimize blood loss in such cases may include use of bone wax, judicious use of electrocautery and bipolar sealer (Aquamantys; Medtronic, Inc, Minneapolis, Minn), limited use of laparotomy pads and discard suction, acute normovolemic hemodilution, rapid autologous priming, small-volume oxygenators with small-diameter tubing and cell salvage, minimal laboratory testing, and intraoperative ultrafiltration. ${ }^{1-5}$

Bhaskar and colleagues ${ }^{1}$ reported results for 49 Witnesses undergoing cardiac surgery. They had significantly less bleeding, almost half that of non-Witness patients. Jassar and colleagues $^{2}$ reported excellent results in 91 Witnesses undergoing cardiac surgery, both elective and urgent, with their bloodless medicine program. Vaislic and colleagues ${ }^{3}$ reported their results for cardiac surgery in 500 consecutive Witnesses, 250 from 1991 to 2003 and 250 from 2003 to 2012. Thirty-day mortalities in the 2 groups were $3 \%$ and $1 \%$, respectively. All these large series demonstrate that progressive advances in perioperative management, improved perfusion techniques, meticulous surgical planning, and a "bloodless team approach" ${ }^{2}$ can allow well-selected Witnesses to undergo even complex cardiac surgery with remarkable safety. These results are possible to obtain with low risk of bleeding.

Our patient underwent reoperation for prosthetic aortic valve infective endocarditis complicated by anemia, thrombocytopenia, and renal failure. The agony that goes into the decision to operate or not for higher risk patients involves the patient, families, and the treating physicians. In the end, if we think we can possibly be successful, we will do it. The patient was extremely lucky that we were able to avoid bleeding completely, probably an important factor in his rapid postoperative reversal of renal function decline. The case illustrates that even a complex, reoperative allograft root replacement procedure can be performed safely in Witnesses. Our case interestingly also demonstrates the potential reversibility of infective endocarditis-induced renal injury.

\section{References}

1. Bhaskar B, Jack RK, Mullany D, Fraser J. Comparison of outcome in Jehovah's Witness patients in cardiac surgery: an Australian experience. Heart Lung Circ. 2010; $19: 655-9$

2. Jassar AS, Ford PA, Haber HL, Isidro A, Swain JD, Bavaria JE, et al. Cardiac surgery in Jehovah's Witness patients: ten-year experience. Ann Thorac Surg. 2012;93:19-25.

3. Vaislic CD, Dalibon N, Ponzio O, Ba M, Jugan E, Lagneau F, et al. Outcomes in cardiac surgery in 500 consecutive Jehovah's Witness patients: 21 year experience. J Cardiothorac Surg. 2012;7:95

4. Coselli JS, Buket S, Van Cleve GD. Successful reoperation for ascending aorta and arch aneurysm in a Jehovah's Witness. Ann Thorac Surg. 1994;58:871-3.

5. Holt RL, Martin TD, Hess PJ, Beaver TM, Klodell CT. Jehovah's Witnesses requiring complex urgent cardiothoracic surgery. Ann Thorac Surg. 2004;78:695-7.

\title{
Long-term outcome of off-pump palliation for hypoplastic left ventricle with glutaraldehyde fixation of the ductus arteriosus
}

\author{
Ryan J. Williams, BS, ${ }^{a}$ Daniel S. Levi, MD, ${ }^{a}$ Jamil Aboulhosn, MD, ${ }^{b}$ and Hillel Laks, MD, ${ }^{c}$ Los Angeles, \\ Calif
}

A newborn with a hypoplastic left heart was palliated with a novel surgical approach including glutaraldehyde fixation of the ductus arteriosus, aortopulmonary shunt placement, and pulmonary artery (PA) reconstruction without cardiopulmonary bypass. The long-term followup is reported.

From the Divisions of Pediatric Cardiology, ${ }^{\mathrm{a}}$ Cardiology, ${ }^{\mathrm{b}}$ and Cardiothoracic Surgery, ${ }^{\mathrm{c}}$ David Geffen School of Medicine at UCLA, Los Angeles, Calif.

Disclosures: Jamil Aboulhosn reports shares in On-X Valve company. All other authors have nothing to disclose with regard to commercial support.

Received for publication March 6, 2012; revisions received May 23, 2014; accepted for publication June 2, 2014.

Address for reprints: Daniel S. Levi, MD, 10833 Le Conte Ave, B2-427 MDCC, Los Angeles, CA 90095 (E-mail: DLevi@mednet.ucla.edu).

J Thorac Cardiovasc Surg 2014;148:e200-2

$0022-5223 / \$ 36.00$

Copyright (c) 2014 by The American Association for Thoracic Surgery

http://dx.doi.org/10.1016/j.jtcvs.2014.06.071

\section{CLINICAL SUMMARY}

A term neonate was born with heterotaxy, dextrocardia, unbalanced atrioventricular canal with regurgitation, double-outlet right ventricle, hypoplastic left ventricle, and aortic atresia with a 3-mm ascending aorta. There were bilateral superior venae cavae and an interrupted inferior vena cava with azygos continuation to the leftsided superior vena cava.

Stage I palliation was performed 7 days after birth (Figure 1). A 4-mm modified right Blalock-Taussig shunt was placed without cardiopulmonary bypass to the right PA. The proximal right PA was divided between clamps at its origin from the main PA and the stump was oversewn, leaving flow to the right PA from the shunt and antegrade flow to the left PA. The proximal left PA was then similarly clamped, divided, and oversewn leaving flow only to the 


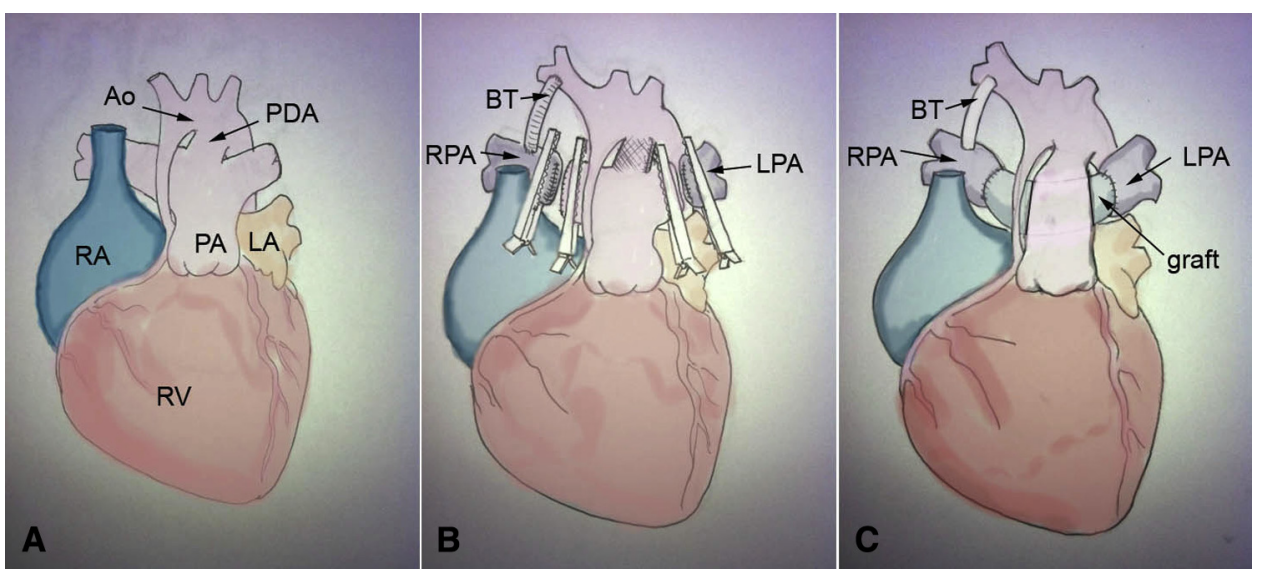

FIGURE 1. A, Preoperative anatomy. B, Division of branch pulmonary arteries and modified right Blalock-Taussig shunt $(B T)$ placement. C, Final result after ductal fixation and restoration of central pulmonary arterial continuity. Ao, Aorta; $P D A$, patent ductus arteriosus; $R A$, right atrium; $P A$, pulmonary artery; $L A$, left atrium; $R V$, right ventricle; $R P A$, right pulmonary artery; $L P A$, left pulmonary artery.

right PA. A tube of pericardium was then used to restore central continuity between the right and left PAs.

After placement of sponges over adjacent structures, the ductus arteriosus was treated with diluted $0.6 \%$ glutaraldehyde solution (equal parts $0.6 \%$ glutaraldehyde and saline solution). Several applications were made along the length of the ductus, allowing the glutaraldehyde to remain on the ductus for at least 1 minute at a time. After each application, the sponges were exchanged and the area copiously irrigated.

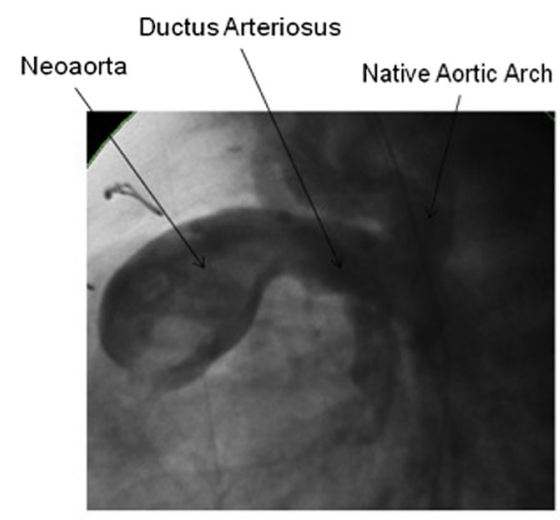

A

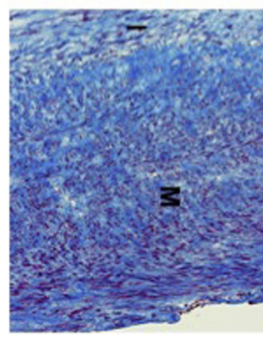

C
After treatment of the ductus with glutaraldehyde, dehiscence of the posterior suture line of the Blalock-Taussig shunt anastomosis to the right PA was noted, necessitating a short period of cardiopulmonary bypass for revision. Postoperatively, the patient's hemodynamics remained stable, with an arterial oxygen saturation of $70 \%$.

Catheterization performed 2 months postoperatively revealed a discrete stenosis in the proximal left PA (minimum diameter of $1.2 \mathrm{~mm}$ ), which was dilated with near-resolution of the stenosis (Figure 2, $A$ and $B$ ). The

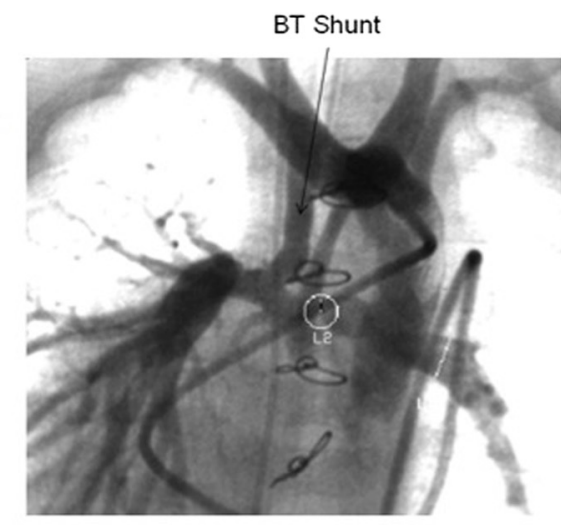

B

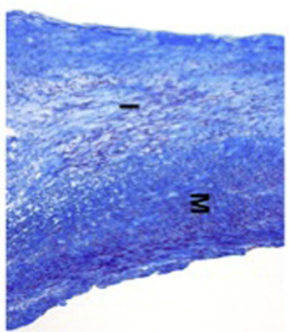

FIGURE 2. A, Angiography of the neoaorta and the native arch (lateral view). B, Contrast injection in the neoaorta filling the pulmonary vasculature through the right Blalock-Taussig (BT) shunt (anteroposterior view). C, Trichrome stain of excised ductus arteriosus tissue revealing fibromuscular hyperplasia of the intima with marked fibrosis of the media $(M)$. 
patient underwent off-pump stage II palliation at 3 months of age with the placement of a right Glenn shunt, central shunt placement, and ligation of the left-sided superior vena cava above the level of the azygos vein. Postoperative echocardiography showed right ventricular hypertrophy with preserved systolic function, mild neoaortic valve insufficiency, unobstructed PA flow, and mild to moderate obstruction at the junction of the neoaorta and the native descending aorta.

At 4 years of age, the patient underwent pericardial patch augmentation of the neoaorta with excision of the previously fixed ductus arteriosus, anastomosis of the azygos continuity of the inferior vena cava to the left PA (Kawashima procedure), central shunt takedown, and augmentation of the central PA with a $12 \mathrm{~mm}$ GORE-TEX graft (W. L. Gore \& Associates, Newark, Del) on cardiopulmonary bypass. Her postoperative course was uneventful, with echocardiography showing minimal neoaortic valve regurgitation with no obstruction of the neoaorta, PAs, Glenn, and Kawashima anastomoses. Pathologic examination of the excised ductus arteriosus tissue is shown in Figure 2, $C$.

The patient presented at 8 years of age with increasing cyanosis secondary to progressive pulmonary arteriovenous malformations, and thus underwent connection of the hepatic veins to the right PA by using a 16-mm GORE-TEX graft with an uneventful postoperative course.

At most recent follow-up, the patient is 8 years old and growing well. There is excellent right ventricular systolic function, mild tricuspid regurgitation, and no neoaortic valve regurgitation on echocardiography. The neoaorta, cavopulmonary connections, and PAs are all unobstructed. The patient's arterial oxygen saturation is $97 \%$ on room air.

\section{DISCUSSION}

Glutaraldehyde fixation of the ductus arteriosus and off-pump shunt placement may represent an alternative to "hybrid" palliation for higher risk neonates with hypoplastic left heart syndrome physiology. Glutaraldehyde treatment of the ductus arteriosus allowed the deferral of arch reconstruction and circulatory arrest for this patient until her stage III operation at the age of 4 years. The treated ductus was not balloon dilatable or stentable in the catheterization laboratory, which has been a consistent finding in patients treated with this technique. The neoaorta itself remained completely unobstructed from the time of fixation until arch reconstruction was performed. Furthermore, there were no apparent adverse effects from the use of glutaraldehyde for ductal fixation.

An additional advantage of the approach is the avoidance of bilateral PA banding. Separating the pulmonary circulation from the neoaorta facilitates the use of aortopulmonary shunts, which may allow for more predictable pulmonary blood flow.

The limitation of this approach is its complexity. This is a difficult operation that is unlikely to become the standard of care for hypoplastic left heart syndrome. Nevertheless, aspects of this approach may be of use in the treatment of selected patients with single-ventricle congenital heart disease requiring aortic arch augmentation.

\title{
Transcatheter implantation of a newly designed aortic prosthesis in a patient with a mechanical mitral valve
}

\author{
Jan-Philipp Minol, MD, ${ }^{\mathrm{a}}$ Verena Veulemanns, MD, ${ }^{\mathrm{b}}$ Tobias Zeus, MD, ${ }^{\mathrm{b}}$ and Alexander Blehm, MD, ${ }^{\mathrm{a}}$ \\ Düsseldorf, Germany
}

Transcatheter aortic valve implantation (TAVI) in patients with previously implanted mechanical mitral valve prosthesis has been reported to be a challenge, particularly

\footnotetext{
From the Departments of Cardiovascular Surgery ${ }^{\mathrm{a}}$ and Cardiology, Pulmonology, and Angiology, ${ }^{\mathrm{b}}$ University Hospital, Düsseldorf, Germany.

Disclosures: Authors have nothing to disclose with regard to commercial support.

Received for publication May 30, 2014; accepted for publication May 30, 2014; available ahead of print Aug 15, 2014

Address for reprints: Jan-Philipp Minol, MD, Department of Cardiovascular Surgery, University Hospital, Moorenstrasse 5, 40225 Düsseldorf, Germany (E-mail: Jan-Philipp.Minol@med.uni.duesseldorf.de).

J Thorac Cardiovasc Surg 2014;148:e202-4

$0022-5223 / \$ 36.00$

Copyright (c) 2014 by The American Association for Thoracic Surgery

http://dx.doi.org/10.1016/j.jtcvs.2014.05.094
}

with respect to positioning. ${ }^{1-3}$ The new Engager aortic valve prosthesis (Medtronic, Inc, Minneapolis, Minn) is designed to capture the native leaflets of the original aortic valve with its control arms by placing it as close to the native aortic annulus as possible, ${ }^{4}$ potentially perfecting the positioning through tactile feedback. We describe TAVI with an Engager valve in a patient with a previously implanted mitral valve.

\section{CLINICAL SUMMARY}

A 81-year-old white women who had severe symptomatic aortic valve disease with prevailing stenosis (New York Heart Association functional class III) was assigned to undergo aortic valve replacement. Echocardiographic 